Provided for non-commercial research and education use. Not for reproduction, distribution or commercial use.

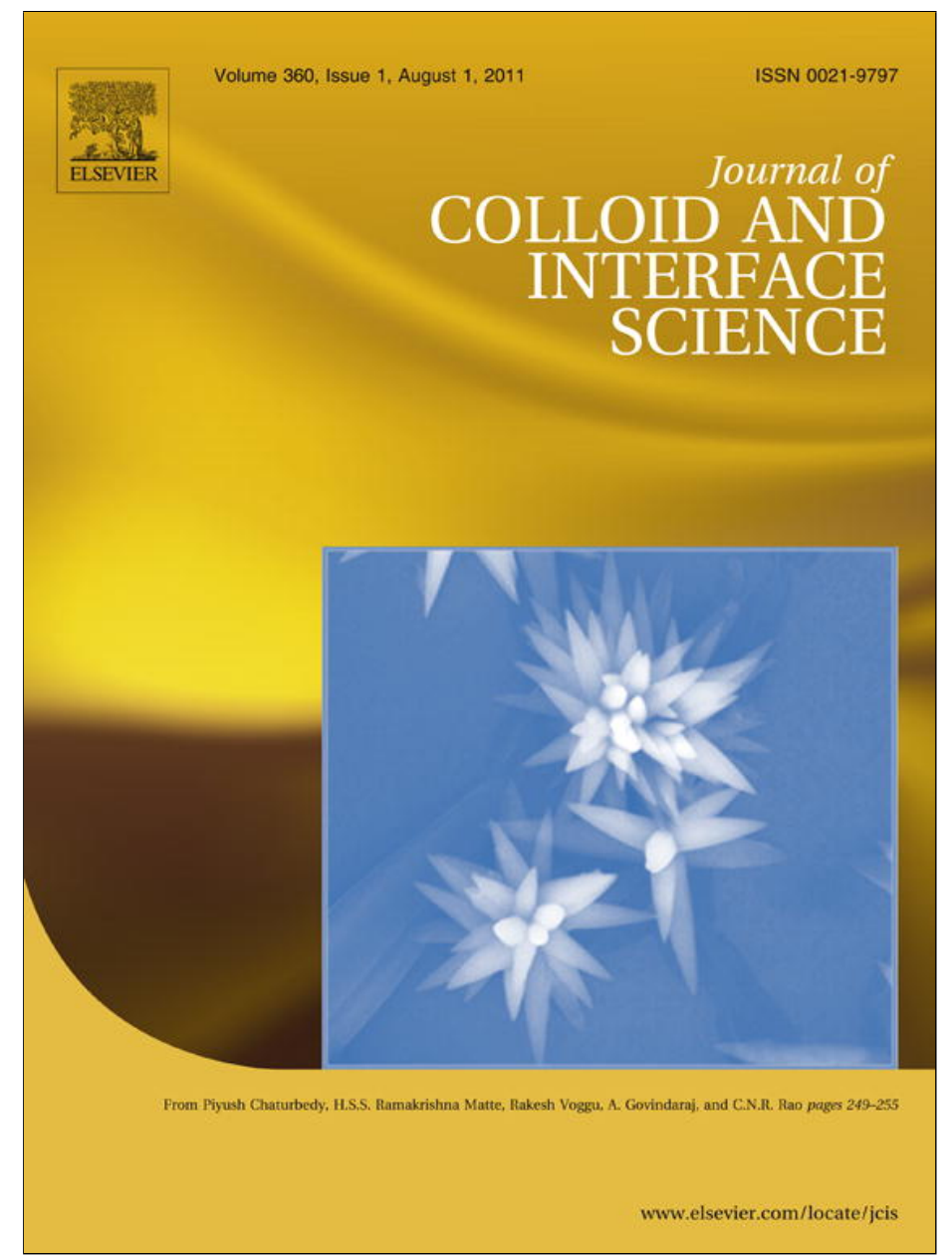

This article appeared in a journal published by Elsevier. The attached copy is furnished to the author for internal non-commercial research and education use, including for instruction at the authors institution and sharing with colleagues.

Other uses, including reproduction and distribution, or selling or licensing copies, or posting to personal, institutional or third party websites are prohibited.

In most cases authors are permitted to post their version of the article (e.g. in Word or Tex form) to their personal website or institutional repository. Authors requiring further information regarding Elsevier's archiving and manuscript policies are encouraged to visit:

http://www.elsevier.com/copyright 


\title{
Analysis of HIV-1 fusion peptide inhibition by synthetic peptides from E1 protein of GB virus $C$
}

\author{
Maria Jesús Sánchez-Martín ${ }^{\mathrm{a}, *}$, Kalina Hristova $^{\mathrm{b}}$, Montserrat Pujol ${ }^{\mathrm{a}}$, Maria J. Gómara ${ }^{\mathrm{c}}$, Isabel Haro ${ }^{\mathrm{c}}$, \\ M. Asunción Alsina ${ }^{a}$, M. Antònia Busquets ${ }^{a}$ \\ ${ }^{a}$ Physical Chemistry Department, Faculty of Pharmacy, University of Barcelona, Associated Unit to the CSIC: Peptides and Proteins: Physicochemical Studies, \\ IN2UB. Av. Joan XXIII \\ $s / n, 08028$ Barcelona, Spain \\ ${ }^{\mathrm{b}}$ Department of Materials Science and Engineering, Johns Hopkins University, Baltimore, MD 21218, USA \\ ${ }^{\mathrm{c}}$ Unit of Synthesis and Biomedical Application of Peptides, Department of Biomedical Chemistry, IQAC-CSIC, Jordi Girona 18, 08034 Barcelona, Spain
}

\section{A R T I C L E I N F O}

\section{Article history:}

Received 28 February 2011

Accepted 12 April 2011

Available online 24 April 2011

\section{Keywords:}

HIV-1 FP inhibition

Hepatitis $G$ virus

Peptide synthesis

Bilayers as model membranes

Giant unilamellar vesicles

Confocal microscopy

\begin{abstract}
A B S T R A C T
The aim of this study was to identify proteins that could inhibit the activity of the peptide sequence representing the $\mathrm{N}$-terminal of the surface protein gp41 of HIV, corresponding to the fusion peptide of the virus (HIV-1 FP). To do this we synthesized and studied 58 peptides corresponding to the envelope protein $\mathrm{E} 1$ of the hepatitis $\mathrm{G}$ virus (GBV-C).

Five of the E1 synthetic peptides: NCCAPEDIGFCLEGGCLV (P7), APEDIGFCLEGGCLVALG (P8), FCLEGGCL VALGCTICTD (P10), QAGLAVRPGKSAAQLVGE (P18) and AQLVGELGSLYGPLSVSA (P22) were capable of inhibiting the leakage of vesicular contents caused by HIV-1 FP. A series of experiments were carried out to determine how these E1 peptides interact with HIV-1 FP. Our studies analyzed the interactions with and without the presence of lipid membranes. Isothermal titration calorimetry revealed that the binding of P7, P18 and P22 peptides to HIV-1 FP is strongly endothermic, and that binding is entropy-driven. Gibbs energy for the process indicates a spontaneous binding between E1 peptides and HIV- 1 FP. Moreover, confocal microscopy of Giant Unilamellar Vesicles revealed that the disruption of the lipid bilayer by HIV-1 FP alone was inhibited by the presence of any of the five selected peptides.

Our results highlight that these E1 synthetic peptides could be involved in preventing the entry of HIV1 by binding to the HIV-1 FP. Therefore, the continued study into the interaction between GBV-C peptides and HIV-1 FP could lead to the development of new therapeutic agents for the treatment of AIDS.
\end{abstract}

(c) 2011 Elsevier Inc. All rights reserved.

\section{Introduction}

In recent years, synthetic peptides have attracted a great deal of attention in the multidisciplinary and emerging field of nanobiomedicine [1-3] due to the chemical diversity which can be tolerated within these nanostructures, their ease of synthesis, their high purity and their low production costs. The multiple applications of these compounds include their use in research, diagnosis and the treatment of viral infections such as AIDS and hepatitis [4-7].

Significant progress has been made in the treatment of human immunodeficiency virus (HIV) infection, but we are still far from the end of the battle against this disease. Current therapy consists of complex treatments of nucleoside analogs, non-nucleoside reverse transcriptase inhibitors, and viral protease inhibitors aimed at specific steps of the HIV replication cycle. These drugs target

\footnotetext{
* Corresponding author. Fax: +34 934035987.

E-mail address: mjsanchez@ub.edu (M.J. Sánchez-Martín).
}

with high specificity, but caution should be exercised because rapid virus turnover in HIV infection can result in the emergence of resistant mutations and subsequent treatment failure $[8,9]$. However, the natural history of hepatitis $G$ virus (GBV-C) infection is, at present, not fully understood and its potential to cause hepatitis in humans is questionable [10].

The GB virus C (GBV-C) was recently investigated in the context of HIV infection, because hepatitis virus infections are very frequent in patients suffering from HIV as they have similar transmission routes. Infection with the hepatitis B (HBV) or C (HCV) virus on AIDS patients has been associated with an impaired survival, and these patients often die from liver failure instead of AIDS [11]. In contrast, previous studies have suggested that people coinfected with HIV and GBV-C exhibit delayed progression of HIV, indicating a beneficial influence of GBV-C on patients with HIV infection [12]. Based on a co-infection model, GBV-C may inhibit HIV by inducing chemokines, down-regulating HIV co-receptor(s), influencing cytokine profiles, and having other as yet undefined effects on the host lymphocytes $[12,13]$. However, the mechanism 
responsible for the beneficial effect that the GBV-C virus exerts on the course of infection caused by HIV has yet to be fully defined.

Jung et al. [14] demonstrated that cells transfected with either infectious RNA or a deletion mutant that expressed the N-terminal third of the polyprotein (including the E1 and E2 coding regions) resulted in inhibition of HIV replication, increased the release of chemokines, and decreased the surface expression of CCR5 compared to cells transfected with antisense GBV-C RNA. This indicates that the envelope proteins may be involved in the inhibition of HIV replication.

Recently, we described certain E2 GBV-C domains that interfere with the HIV-1 FP-vesicle interaction, decrease the cellular membrane fusion, and interfere with the HIV-1 infectivity in a dosedependent manner [15].

Taking into account the attractive properties of synthetic peptides and the possible relation between the envelope GBV-C proteins and the inhibition of HIV replication, we studied the capacity of GBV-C E1 peptide sequences to inhibit the interaction and destabilization process of membranes induced by the fusion peptide (FP) of HIV-1. To achieve this, 58 E1 peptides from GBV$C$ were synthesized and characterized.

Recent studies have reported the importance of leakage experiments or isothermal titration calorimetry studies [16-19] in understanding the membrane interacting properties of synthetic peptides. Thus, several biophysical techniques were used to cover different aspects of GBV-C peptide/HIV-1 FP interaction in the presence and absence of lipid vesicles. As a first indication of the ability of GBV-C sequences to inhibit pore formation caused by HIV-1 FP we chose the leakage of the vesicular content assay $[16,17,20]$. From the results of this initial test, five sequences were selected for further studies. Then, the binding of these selected peptide sequences to large unilamellar vesicles was studied by comparing two separation methods: centrifugation and equilibrium dialysis. The same experiment was used to study the E1 peptides inhibition capacity towards HIV-1 FP binding. The thermodynamics of peptide-peptide interaction in solution was also analyzed by isothermal titration calorimetry. Finally, the inhibition effect was observed using a confocal microscopy.

As far as the lipid composition is concerned, whenever possible we chose negatively charged phospholipids because it was found that HIV-1 FP binds stronger to negative phospholipids than to lipid devoid of charge. The exception was the preparation of giant unilamellar vesicles where a zwitterionic lipid was used but labeled with a negative probe, therefore giving a global negative charge.

Our results indicate the capacity of certain peptide sequences of the GBV-C E1 protein to inhibit the fusion process of liposomes induced by the FP of the HIV-1 glycoprotein gp41.

\section{Experimental}

\subsection{Materials}

Amino acids and Rink amide resin (Tentagel R RAM, $0.19 \mathrm{meq} / \mathrm{g}$ ) were obtained from Novabiochem (Nottingham, UK). Dimethylformamide (DMF) was purchased from Scharlau (Barcelona, Spain). Dichloromethane (DCM) and piperidine were purchased from Flu$k a$ (Neu-Ulm, Germany). Acetic acid, diethyl ether, and trifluoroacetic acid (TFA) were obtained from Merck (Poole, Dorset, UK). $N$-hydroxybenzotriazole (HOBt) and $N, N^{\prime}$-diisopropylcarbodiimide (DIPCDI) coupling reagents were obtained from Fluka and Novabiochem, respectively. Other coupling reagents such as $\mathrm{O}$-(7-azabenzotriazole-1-yl)-N, N,N'N'-tetramethyluronium hexafluorophos phate (HATU) and $N, N^{\prime}$-diisopropylethylenamine (DEIA) were obtained from GenScript Corporation and Fluka, respectively. Scaveng- ers such as ethanedithiol (EDT) and triisopropylsilane (TIS) were obtained from Sigma-Aldrich.

1,2-dimyristoyl-sn-glycero-3-phosphocholine (DMPC), 1-palmitoyl-2-oleoyl-sn-glycero-3-phosphocholine (POPG), and 1,2di-(9,10-dibromo) stearoyl-sn-glycero-3-phosphocholine (Br-PC) and Rho-PE [(1,2-dioleoyl-sn-glycero-3-phosphoethanolamine-N(lissamine rhodamine B sulfonyl) (ammonium salt) (18:1 lissamine rhodamine PE)] were purchased from Avanti Polar Lipids. The purity of these lipids was above $99 \%$ and they were used without further purification.

Chloroform and methanol were purchased from Merck. Water was double distilled and deionized (MilliQ system, Millipore) (18.2 $\mathrm{M} \Omega \mathrm{cm}, \mathrm{pH}$ 5.8). The buffer used in all experiments was HEPES (from Sigma-Aldrich) $5 \mathrm{mM}$ and $\mathrm{NaCl}$ (from Merck) $20 \mathrm{mM}$, pH 7.4.

\subsection{Peptides synthesis}

A scan of the GBV-C E1 protein (Genbank D90600, Japan) was carried out by the semiautomatic multiple syntheses of 18-mer peptides overlapped by fifteen residues. The resulting 58 linear peptides were synthesized on a Multisyntech synthesizer using a Tentagel R RAM resin $(0.19 \mathrm{meq} / \mathrm{g})$. This resin enables carboxamide peptides to be obtained at the C-terminal end, by a solid phase methodology following an Fmoc/tBu strategy by means of HATU and DEIA activation. Side protection was effected by the following: 2,2,5,7,8-pentamethyl-chroman-6-sulfonyl (Pmc) for Arg, tert-Butyl (tBu) for Tyr, Ser, Thr and Asp and t-butyloxycarbonyl (Boc) for Lys and Trp. Threefold molar excess of Fmoc-amino acids was used throughout the synthesis. In the manual synthesis, the stepwise addition of each residue was assessed by the Kaiser's (ninhydrin) test [21] and repeated couplings were carried out when a positive ninhydrin test was obtained.

The synthesized peptides were deprotected from the side-chain groups and cleaved from the resin with a treatment of trifluoroacetic acid (TFA) containing appropriate proportions of scavengers [22] such as $\mathrm{H}_{2} \mathrm{O}$, triisopropylsilane (TIS), and ethanedithiol (EDT): 94\% TFA: 2.5\% $\mathrm{H}_{2} \mathrm{O}: 2.5 \%$ EDT: $1 \%$ TIS.

Peptides were characterized using an analytical HPLC Perkin Elmer with an LC-235 Diode Array Detector and a Binary LC Pump 250; the column used was a KROMASIL $100 \mathrm{C} 185 \mu \mathrm{m}$ of $25 \times 0.46 \mathrm{~cm}$. The analysis was carried out using a linear gradient of $95 \% \mathrm{H}_{2} \mathrm{O}\left(0.05 \%\right.$ TFA)/5\% acetonitrile (0.05\% TFA) to $5 \% \mathrm{H}_{2} \mathrm{O}$ $(0.05 \%$ TFA)/95\% acetonitrile (0.05\% TFA). The characterization by electrospray mass spectrometry was carried out using UPLC-MS (AQUITY Ultra Performance LC $^{\mathrm{TM}}$ from Waters, using a BEH C18 column of $1.7 \mu \mathrm{m}, 2.1 \times 100 \mathrm{~mm}$ ). The peptides were purified to as much as $90 \%$ by analytical HPLC at $215 \mathrm{~nm}$ (for further details see Supporting information, Table 1 ).

Peptides synthesized manually (P7, P8, P10, P18 and P22) were purified by semi-preparative HPLC in a Kromasil-C8 column and characterized by ES-MS, achieving a final purity of over $95 \%$.

The fusion peptide of the HIV-1 glycoprotein gp41, HIV-1 FP/ AVGIGALFLGFLGAAGSTMGAAS, was also synthesized by manual SPPS but using a $100 \%$ polyethylene glycol-based ChemMatrix resin that proved to be a more effective support for the solid-phase synthesis of hydrophobic and highly structured peptides. The final purity of the peptides achieved using HPLC was higher than $95 \%$.

\subsection{Preparation of lipid vesicles}

\subsubsection{Large unilamellar vesicles}

Phospholipids were dissolved in a chloroform:methanol $(2: 1, \mathrm{v} /$ v) mixture and the solutions were evaporated to dryness in a vacuum with a rotary evaporator. The dried lipid film was subjected to a high vacuum overnight to remove trace amounts of solvent. Then, the lipid films were hydrated with Hepes buffer $(5 \mathrm{mmol} / \mathrm{L}$, 
$\mathrm{pH}$ 7.4) containing $\mathrm{NaCl} 20 \mathrm{mM}$ to obtain multilamellar vesicles (MLVs). MLVs were further transformed to large unilamellar vesicles (LUVs) by extrusion under moderate pressure through a polycarbonate filter of $0.1 \mu \mathrm{m}$ pore size [23]. The lipid concentration of the stock solutions was $1.5 \mathrm{mM}$.

\subsubsection{Giant unilamellar vesicles}

Giant liposomes were made using the gentle hydration method [24-26] of DMPC films doped with glucose [27] but with slight differences in the preparation method.

Two solutions of (i) DMPC $10 \mathrm{mM}$ in chloroform and (ii) glucose $20 \mathrm{mM}$ in methanol were prepared. Solutions containing $50 \mu \mathrm{L}$ of DMPC and $250 \mu \mathrm{L}$ of glucose were then mixed with $0.6 \%$ of Rho$\mathrm{PE}$, which acted as a labeling probe to allow us to view the vesicles during the confocal microscopy experiments. The mixture was evaporated in the rotary evaporator to form the film and dried under a nitrogen stream for $1 \mathrm{~h}$. The dry lipid film was hydrated with $2 \mathrm{~mL}$ of distilled water and the liposomes left to grow at $40{ }^{\circ} \mathrm{C}$ for $24 \mathrm{~h}$. The cloud of vesicles formed was then collected.

\subsection{Leakage of vesicular contents: ANTS/DPX assay}

For the ANTS (8-aminonaphtalene-1,3,6-trisulfonic acid)-DPX $\left(N, N^{\prime}\right.$-p-xylene-bis(pyridinium bromide) leakage assay [28,29], approximately $20 \mathrm{mg}$ of POPG was dissolved in a mixture of chloroform and methanol (2:1), which was subsequently removed under a stream of nitrogen. Approximately $2 \mathrm{~mL}$ of buffer was added to the dry lipid. The buffer contained $12.5 \mathrm{mM}$ ANTS and $45 \mathrm{mM}$ DPX from Molecular Probes (Eugene, OR) and $20 \mathrm{mM} \mathrm{NaCl}$ and $5 \mathrm{mM}$ Hepes. The osmolarity of the ANTS/DPX solution was adjusted so that it was equal to that of the buffer in a cryoscopic osmometer (Fiske One-ten). The suspension was frozen and thawed 10 times to ensure maximum entrapment prior to extrusion [30]. A stock solution of LUV of approximately $0.1 \mu \mathrm{m}$ in diameter was formed by extrusion pressure through Nucleopore polycarbonate membranes. The vesicles were separated from unencapsulated material on Sephadex G-75 (Pharmacia, Uppsala, Sweden), and equilibrated with $100 \mathrm{mM} \mathrm{NaCl} / 5 \mathrm{mM}$ Hepes buffer ( $\mathrm{pH}$ 7.4). The final concentration of the lipid was $0.1 \mathrm{mM}$.

Fluorescence was measured in an Aminco Bowman AB2 (Microbeam, SA) spectrofluorimeter before and after detergent was added. Before being added to the suspension of LUVs, each GBV-C peptide sequence corresponding to the E1 protein was incubated for 30 min with the HIV-1 FP in dimethylsulfoxide (DMSO). Following this, the fluorescence was measured again. The amount of DMSO, with respect to the total volume of the assay, was always less than $5 \%$. No significant differences in fluorescence were observed when adding the equivalent volume of DMSO in the absence of a peptide. The dequenching of co-encapsulated ANTS and DPX fluorescence resulting from dilution was measured to assess the leakage of aqueous contents from vesicles. Leakage was monitored by measuring the increase in the ANTS/DPX fluorescence intensity at $520 \mathrm{~nm}$, with an excitation of $355 \mathrm{~nm}$ and slits of $8 \mathrm{~nm}$. HIV-1 FP/E1 peptide ratios ranged from $1 / 1$ to $1 / 20$. The percentage of leakage was calculated according to the equation below:

\%leakage $=\frac{\left(F-F_{0}\right)}{\left(F_{100}-F_{0}\right)} \times 100$

where $F_{0}$ is the initial fluorescence of LUVs, $F$ is the fluorescence intensity after adding the peptide, and $F_{100}$ is the fluorescence intensity after the addition of $10 \mu \mathrm{L}$ of a $10 \%(\mathrm{v} / \mathrm{v})$ Triton- 100 solution (complete lysis of LUVs).

\subsection{Peptide binding to lipid vesicles}

HPLC has been previously used for the determination of peptide concentrations in the presence of LUV [31]. The column used was a VYDAC $218 T$ T $54 \mathrm{C} 18$ of $5 \mu \mathrm{m}, 25 \times 0.46 \mathrm{~cm}$. The analysis was carried out using a linear gradient of $95 \% \mathrm{H}_{2} \mathrm{O}(0.05 \%$ TFA $) / 5 \%$ acetonitrile $\left(0.05 \%\right.$ TFA) to $5 \% \mathrm{H}_{2} \mathrm{O}(0.05 \%$ TFA $) / 95 \%$ acetonitrile $(0.05 \%$ TFA) for $30 \mathrm{~min}$ and absorbance was monitored at $215 \mathrm{~nm}$. Two separation methods were used to determine the amount of peptide bound to lipid vesicles.

\subsubsection{Centrifugation method}

The protocol developed by White et al. [32] was followed in this study. Briefly, an aliquot of a mixture of peptide and liposomes is centrifuged to separate peptides bound to the vesicles from those that are unbound. Subsequently, the sediment holds the fraction containing the peptide bound to the lipid vesicles, while the free unbound peptide remains in the supernatant.

In order to facilitate vesicles sedimentation, we used LUVs made with Br-PC, of which $20 \%$ was POPG. The brominated lipid is used because it enables the liposomes in a centrifugal field to be sedimented, and the negatively-charged lipid is required to facilitate the highest interaction possible between the HIV-1 FP and the liposomes.

Stock solutions of $1 \mathrm{mg} \mathrm{ml}^{-1}$ of E1 peptides were used. Appropriate volumes of these peptides were selected to obtain a final concentration of $0.2 \mathrm{mM}$ in the final mixture with the brominated liposomes. E1 peptides were incubated with the HIV-1 FP in DMSO for a period of $30 \mathrm{~min}$ at a molar ratio HIV-1 FP:E1 peptide of 1:20. The E1 peptides alone and the mixtures of both peptides were then incubated with the brominated liposomes $(0.565 \mathrm{mM})$ for a period of $30 \mathrm{~min}$; an aliquot of the lipid-peptide solution was withdrawn for the HPLC analysis of total peptide and the samples were then sedimented using a Microfuge ${ }^{\circledR} 18$ Centrifuge of Beckman Coulter $^{\mathrm{TM}}$. The sedimentation was done progressively by spinning at 4500,9000 and then $16,000 \mathrm{~g}$ for 30 min each time so that the liposomes were sedimented gently at first and then spun into a tight pellet. Following this, the peptide concentration of the supernatant was analyzed by HPLC as described before.

\subsubsection{Equilibrium dialysis}

The basic principle of equilibrium dialysis is that two half cells, one containing a small volume of lipid solution and the other containing buffer, are separated by a membrane that is permeable to peptides but impermeable to lipid vesicles. We used the RED (rapid equilibrium dialysis) Device Inserts from Thermo Scientific and a Teflon ${ }^{\circledR}$ high-grade Reusable Base Plate. The sampling of total and free peptide is done directly in an equilibrium dialysis, and there is an explicit assumption that the free peptide has the same concentration on both sides of the dialysis membrane [33].

To determine the incubation time necessary to achieve the equilibrium, $200 \mu \mathrm{L}$ of a solution of peptide $0.5 \mathrm{mg} \mathrm{ml}^{-1}$ in DMSO were added to the sample chamber and $350 \mu \mathrm{L}$ of buffer were added to the buffer sample. The device was then incubated at room temperature at approximately $100 \mathrm{rpm}$ on an orbital shaker. An aliquot of each chamber was analyzed by HPLC after 4, 24 and $48 \mathrm{~h}$.

To run the binding experiments, the E1 peptides were incubated with HIV-1 FP, in a molar ratio of 1:20, and then with liposomes as in the centrifugation assay, before adding them to the sample chamber. After $48 \mathrm{~h}$, the samples were analyzed by HPLC.

\subsection{Isothermal titration calorimetry}

Isothermal titration calorimetric (ITC) experiments were recorded on a VP-ITC micro-calorimeter (MicroCal, LLC, Northampton, MA). All the peptides were dissolved in DMSO. Briefly, a 
solution of $1 \mathrm{mg} \mathrm{ml}^{-1}$ of $\mathrm{E} 1$ peptides was injected into the chamber containing $25 \mu \mathrm{M}$ HIV-1 FP. The calorimeter was first equilibrated at $20^{\circ} \mathrm{C}$, and the baseline was monitored during equilibration. The time between injections was $10 \mathrm{~min}$, and the stirring speed was $300 \mathrm{rpm}$. The heats of dilution were determined in control experiments by injecting E1 peptides into DMSO. They were then subtracted from the heats produced in the corresponding peptidepeptide binding experiments. Control experiments were also performed by titrating DMSO into HIV-1 FP. The total observed heat effects were corrected for these small contributions. All titration data were subsequently analyzed using the Origin 7 software (MicroCal, LLC).

\subsection{Confocal microscopy}

Confocal microscopy studies were run to visualize how HIV-1 FP affected liposomes and to assess whether the E1 peptides were capable of inhibiting the activity of HIV-1 FP. Experiments were performed in an Olympus Fluoview (FV500) with an Olympus IX70 microscopy associated.

Firstly, the HIV-1 FP was incubated during 30 min with E1 synthetic peptides at different molar ratios, which were 1:1, 1:10 and $1: 20$. As the results for $1: 10$ and $1: 20$ were similar, the lower molar ratio (1:10) was selected to run all the experiments, moreover, this molar ratio also gave good results in the leakage of vesicular contents assay. Following this, $50 \mu \mathrm{L}$ of liposomes were added to this mixture (1:10), $50 \mu \mathrm{L}$ were added to HIV-1 FP alone and $50 \mu \mathrm{L}$ of liposomes were used as a control. Subsequently, the mixtures were subjected to fixation with $3.2 \%$ of p-formaldehyde [34] to avoid the aggregation of the liposomes.

\section{Results and discussion}

\subsection{Leakage of vesicular contents: ANTS/DPX assay}

After synthesizing 58 overlapped peptides of the envelope protein E1 of GBV-C, the initial proposed work was the study of their capacity to inhibit the interaction and destabilization processes of membranes, induced by HIV-1 FP. This was carried out using the vesicular content leakage assay, as previously described for the E2 GBV-C sequences [15].

The biophysical assay on the vesicle contents release $[16,17,20]$ was used to select the appropriate E1 GBV-C peptide sequences. Firstly, HIV-1 was tested for its ability to induce leakage from large unilamellar phospholipid vesicles (LUVs) of a defined composition. POPG LUVs were used as it was previously reported that HIV-1 binds to negative phospholipids more strongly than to lipids with no net charge [35].
For the assay, a stock solution of $1 \mathrm{mg} \mathrm{ml}^{-1}$ of HIV-1 FP in DMSO was used and E1 peptides were dissolved to a concentration of $0.2 \mathrm{mg} \mathrm{ml}^{-1}$. The volume of HIV-1 FP solution providing approximately half of the total vesicle contents release was selected and each GBV-C peptide sequence corresponding to the E1 protein was incubated for $30 \mathrm{~min}$ with this concentration of HIV-1 FP. The molar ratio was 1:20 and each experiment was repeated three times.

We found that 53 peptides destabilized the membranes in the same way as the fusion peptide. Only five of the peptides were capable of inhibiting the vesicle contents leakage caused by HIV1 FP (Fig. 1a) at a molar ratio of 1:20 (HIV-1 FP:E1 peptide). These peptides were named P7, P8, P10, P18 and P22, which correspond to regions the E1(19-36), E1(22-39), E1(28-45), E1(52-69) and E1(64-81), respectively.

Several ratios of the HIV-1 fusion peptide and these 5 peptides $(1: 1,1: 2,1: 5,1: 10$ and 1:20) were tested in the leakage assay. As shown in Fig. 1b, when the proportions of the E1 peptides were low, inhibition did not occur. Taking into account that the amount of HIV-1 FP used provides approximately half of the total vesicle contents release (horizontal red line), we observed that for P8 and P22 we needed a minimum molar ratio of 1:10 to decrease the percentage leakage to under 50\%. For P7, P10 and P18 a molar ratio of $1: 5$ was enough to decrease the \% leakage. Below these molar ratios, the leakage obtained was equal to the sum of the leakage caused by the HIV-1 FP and by the E1 peptides.

Results found in this experiment indicate a dual behavior of the peptides. In general, at low E1 peptide concentrations, leakage caused by the HIV-1 FP is not inhibited but rather it increases as a consequence of a synergism between the HIV-1 FP and E1 sequences. Above a certain molar ratio, depending on the peptide, leakage is not completely but highly inhibited. These five peptides were selected for the subsequent studies to corroborate their capacity of inhibition of the vesicle contents leakage caused by HIV-1 FP.

\subsection{Peptide binding to lipid vesicles}

\subsubsection{Centrifugation method}

For this assay a brominated phosphocholine (Br-PC) was required to ensure the separation of the liposome-peptide(s) complex. The first question proposed was whether HIV-1 FP would interact with liposomes composed of zwitterionic phospholipids such as Br-PC, because HIV-1 FP binds more effectively to negatively charged phospholipids. Therefore, we needed to know the minimal amount of POPG in Br-PC liposomes that yielded the maximal percentage of leakage in the presence of HIV-1 FP. Thus, the
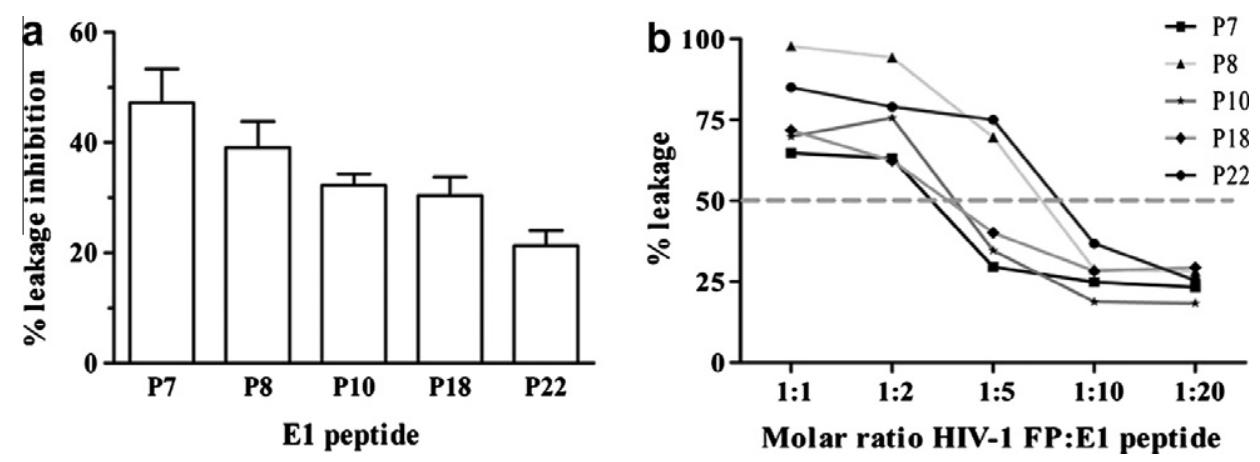

Fig. 1. (a) Inhibitory effect of E1 GBV-C peptides on HIV-1 FP induced leakage. The molar ratio of the HIV-1FP:E1 peptide is $1: 20$. (b) HIV-1 fusion peptide leakage in the presence of P7,P8,P10,P18 and P22 at different molar ratios. E1 peptides were incubated with the HIV-1 FP amount that causes 50\% of leakage (dotted line). Molar ratio POPG/ HIV-1 FP: 5/1. All experiments were repeated three times. 
first step was to repeat the leakage assay for the HIV-1 FP using liposomes with different molar ratios of POPG and Br-PC.

The amount of HIV-1 FP that provided approximately half of the total vesicle contents release of pure POPG vesicles was tested and was used for all the phospholipid mixtures. The results are shown in Fig. 2.

We found that the leakage of solutes from $\mathrm{Br}-\mathrm{PC}$ vesicles was low (approximately 15\%), but increased more than 4-fold in the presence of POPG. The leakage was similar for all POPG concentrations, ranging from $20 \%$ to $100 \%$. While this appears surprising since charge interactions are believed to play a major role in the peptide-lipid interactions that we have studied. However, the close proximity of the POPG headgroups at high POPG concentrations can shift the pKa of these headgroups, such that the fraction of charged POPG lipids does not vary much above 20\% POPG. Thus, the mixture POPG:Br-PC 20:80 was selected for the binding experiments, as it contains 20\% POPG to ensure strong binding, as well as $80 \% \mathrm{Br}-\mathrm{PC}$, to ensure the sedimentation of the liposomes upon centrifugation. Liposomes were incubated with the peptides alone and with mixtures of HIV-1 FP and E1 peptides.

The initial amount of peptide was analyzed by HPLC before centrifugation. This value corresponded to the total concentration of peptide added that can bind to LUVs. Free peptide or unbound peptide concentration was measured under the same analytical conditions from the supernatant after centrifugation. Each determination was done in triplicate.

The results are shown in Table 1. For P7 and P18 when incubated with HIV-1 FP, the percentage of E1 peptides bound increased, while the percentage of bound HIV-1 FP decreased, showing the inhibition of the interaction of HIV-1 FP with liposomes. For P10 and P22 the percentage of bound E1 peptides decreased, as did the binding of HIV-1 FP to liposomes. The only peptide that seemed to have no interaction with HIV-1 FP was

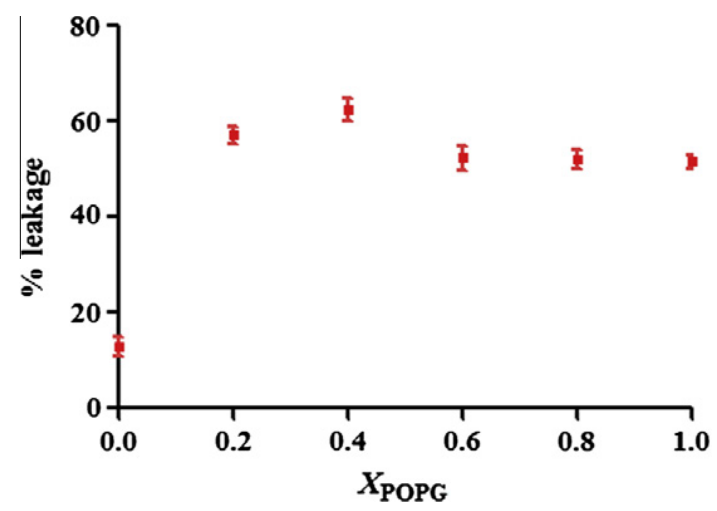

Fig. 2. Percentage of leakage of vesicular contents (ANTS/DPX loaded LUVS) caused by HIV-1 FP to liposomes with different molar ratios of POPG:Br-PC, expressed as molar fraction of POPG. Each point is the average of at least three determinations.

Table 1

Percentage of bound E1 peptides in the presence and absence of HIV-1 FP bound to POPG:Br-PC liposomes.

\begin{tabular}{lrc}
\hline & \% Bound El peptide & \% Bound HIV-1 FP \\
\hline HIV-1 FP & & $76.3 \pm 0.2$ \\
P7 & $-0.4 \pm 0.1$ & \\
P7 + HIV-1 FP & $21.2 \pm 0.0$ & $8.0 \pm 0.1$ \\
P8 & $22.8 \pm 0.5$ & \\
P8 + HIV-1 FP & $19.9 \pm 0.5$ & $76.1 \pm 0.4$ \\
P10 & $23.0 \pm 0.6$ & \\
P10 + HIV-1 FP & $4.3 \pm 0.4$ & $38 . \pm 0.4$ \\
P18 & $1.7 \pm 0.1$ & $3.2 \pm 0.2$ \\
P18 + HIV-1 FP & $12.7 \pm 0.2$ & \\
\hline
\end{tabular}

Table 2

Mole fraction partition coefficients of E1 synthetic peptides and HIV-1 FP separately and when mixed.

\begin{tabular}{lll}
\hline & Kx (El peptides) & Kx (HIV-1 FP) \\
\hline P7 & No binding & \\
P7 + HIV-1 FP & $6.43 \times 10^{5}$ & $2.04 \times 10^{5}$ \\
P8 & $8.67 \times 10^{5}$ & \\
P8 + HIV-1 FP & $5.75 \times 10^{5}$ & $7.50 \times 10^{6}$ \\
P10 & $8.65 \times 10^{5}$ & \\
P10 + HIV-1 FP & $6.45 \times 10^{4}$ & $9.34 \times 10^{5}$ \\
P18 & $6.04 \times 10^{4}$ & \\
P18 + HIV-1 FP & $2.12 \times 10^{5}$ & $4.89 \times 10^{4}$ \\
P22 & $9.19 \times 10^{5}$ & \\
P22 + HIV-1 FP & No binding & $2.94 \times 10^{5}$ \\
HIV-1 FP & $4.68 \times 10^{6}$ & $4.68 \times 10^{6}$ \\
\hline
\end{tabular}

P8; as the activity of HIV-1 FP remained equal, it seems that P8 and HIV-1 FP act independently, in the same way as in the leakage assay when a molar ratio of below 1:10 was used. Negative values appeared when there was no binding (due to experimental errors).

The data obtained in this study allowed us to calculate the mole fraction partition coefficient of the peptides following Equation 2:

$K_{x}=\frac{\left([P]_{\text {total }}-[P]_{\text {free }}\right) /[L]}{[P]_{\text {free }} /[W]}$

where $[P]_{\text {total }}$ and $[P]_{\text {free }}$ are the aqueous peptide concentrations measured before and after the centrifugation, respectively, and $[L]$ and $[W]$ are the molar concentrations of lipid and water [32].

The results are shown in Table 2 . We observed that the partition coefficients of HIV-1 FP decreased when mixed with peptides that inhibit its activity.

\subsubsection{Equilibrium dialysis}

We measured the time required to reach the equilibrium as explained above and found it to be $48 \mathrm{~h}$ for all samples. We then carried out two series of experiments: firstly, we added the liposomes to the sample cell that was the one that will contain the peptides and secondly we added the liposomes to the buffer cell. In both cases, after $48 \mathrm{~h}$, the E1 peptides were equilibrated between the sample cell and the buffer cell, indicating that there is no interaction with the liposomes, independently of whether they are alone or mixed with the fusion peptide.

In all cases, however, the amount of HIV-1 FP remaining with the peptides was higher than in the buffer cell. The results obtained are shown in Table 3. The values correspond to the average of three determinations. We found that when the liposomes were in the same cell as HIV-1 FP alone, it was not equilibrated, which could mean that there is an interaction between HIV-1 FP and the liposomes, forming a complex that could not pass through the membrane. Thus, when HIV-1 FP was mixed with the E1 peptides we could not deduce whether there was an interaction between them or whether it was simply bound to the liposomes. Although for P18, the amount of HIV-1 FP remaining in the sample cell was higher. When the liposomes were added to the buffer cell, HIV-1 FP was equilibrated between both cells, except when in the presence of the E1 peptides. This could be evidence of an interaction between E1 peptides and HIV-1 FP in solution.

\subsection{Isothermal titration calorimetry}

To asses this interaction further, thermodynamic parameters associated with the binding of E1 peptides to HIV-1 FP were determined by isothermal titration calorimetry (ITC). A binding curve was then obtained from a plot of the heats from each injection against the ratio of ligand and binding partner in the cell. Therefore, the results from an ITC can provide an insight into the 
Table 3

Percentage of HIV-1 FP incubated with E1 peptides in a molar ratio of 1:20 present after $48 \mathrm{~h}$ of equilibrium dialysis. Experiments were carried out by adding the liposomes to the same cell of HIV-1 FP (sample cell) and then adding them separately.

\begin{tabular}{llrlll}
\hline & \multicolumn{2}{l}{ Liposomes in sample cell } & & \multicolumn{2}{l}{ Liposomes in buffer cell } \\
\cline { 2 - 3 } \cline { 5 - 6 } & $\begin{array}{l}\text { \% HIV-1 FP } \\
\text { sample cell }\end{array}$ & $\begin{array}{r}\text { \%HIV-1 FP } \\
\text { buffer cell }\end{array}$ & & $\begin{array}{l}\text { \% HIV-1 FP } \\
\text { sample cell }\end{array}$ & $\begin{array}{l}\text { \% HIV-1 FP } \\
\text { buffer cell }\end{array}$ \\
\hline P7 & $83.7 \pm 0.4$ & $16.3 \pm 0.1$ & & $62.5 \pm 0.6$ & $34.8 \pm 0.3$ \\
P8 & $87.9 \pm 0.4$ & $12.1 \pm 0.4$ & & $74.7 \pm 0.4$ & $25.3 \pm 0.1$ \\
P10 & $73.4 \pm 0.3$ & $26.6 \pm 0.2$ & & $67.1 \pm 0.4$ & $32.9 \pm 0.4$ \\
P18 & $92.5 \pm 0.1$ & $7.5 \pm 0.2$ & & $81.2 \pm 0.5$ & $18.8 \pm 0.4$ \\
P22 & $85.2 \pm 0.0$ & $14.8 \pm 0.4$ & & $78.6 \pm 0.3$ & $21.4 \pm 0.2$ \\
HIV-1 FP & $82.5 \pm 0.1$ & $17.5 \pm 0.3$ & $50.6 \pm 0.4$ & $49.4 \pm 0.3$ \\
\hline
\end{tabular}

Table 4

Physicochemical parameters corresponding to the reaction between HIV-1 FP and E1 synthetic peptides.

\begin{tabular}{lllllc}
\hline & $\begin{array}{l}\Delta H / \mathrm{kcal} / \\
\mathrm{mol}\end{array}$ & $\begin{array}{l}-T \Delta S / \mathrm{kcal} / \\
\mathrm{mol}\end{array}$ & $N$ & $K_{a} / \mathrm{M}^{-1}$ & $\begin{array}{c}\mathrm{Kd} / \\
\mu \mathrm{M}\end{array}$ \\
\hline P7 & $3.21 \pm 0.34$ & -10.46 & $0.47 \pm 0.04$ & $2.03 \pm 0.46 \times 10^{5}$ & 4.93 \\
P18 & $9.32 \pm 0.81$ & -15.646 & $0.73 \pm 0.05$ & $4.33 \pm 0.30 \times 10^{4}$ & 23.1 \\
P22 & $9.60 \pm 0.40$ & -16.09 & $0.88 \pm 0.03$ & $6.12 \pm 0.31 \times 10^{4}$ & 16.3 \\
\hline
\end{tabular}

dominant forces associated with binding $[19,36]$. Due to the insolubility of the HIV-1 FP, a microcalorimetry titration experiment was performed using DMSO as a solvent. For P8 and P10 the system did not reach saturation, while for P7, P18 and P22 the heat signal diminished until only heats of dilution were observed. The corresponding binding curves are shown in Fig. 3. The binding of P7, P18 and P22 to HIV-1 FP was endothermic, indicated by positive peaks. The hyperbolic titration curve demonstrates that the binding site of HIV-1 FP was saturated with the corresponding peptide (Fig. 3 top). The cumulative reaction enthalpy as a function of the peptide molar ratio is shown in Fig. 3 (bottom). The solid line corresponds to the best theoretical fit to the experimental data. The binding enthalpy $(\Delta H)$ of the GBV-C peptides to the HIV-1 FP and the entropy change $(\Delta S)$ are shown in Table 4.

This information provides insight into the dominant forces driving the association between E1 peptides and HIV-1 FP. The binding of these peptides is strongly endothermic ( $\Delta H$ positive) and binding is entropy-driven. The negative Gibbs energy $(\Delta G)$, defined as $\Delta G=\Delta H-T \Delta S$, indicates that the binding of these two peptides is spontaneous. The binding stoichiometry $(N)$ of E1 peptides to HIV-1 FP is approximately 1:1 for P18 and P22 and 2:1 for P7.

$N=$ Stoichiometry; $K_{a}=$ association constant; $K_{d}=$ dissociation constant

Time $(\mathrm{min})$

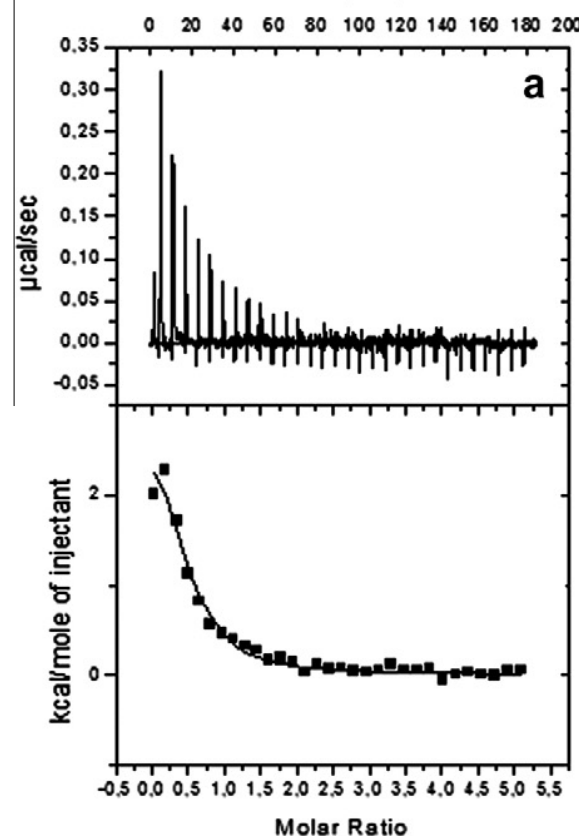

Time (min)

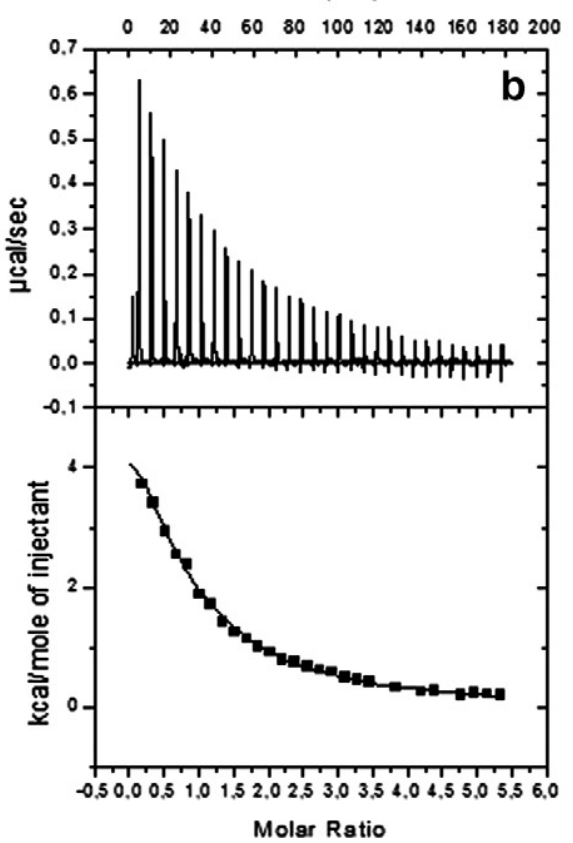

Time (min)

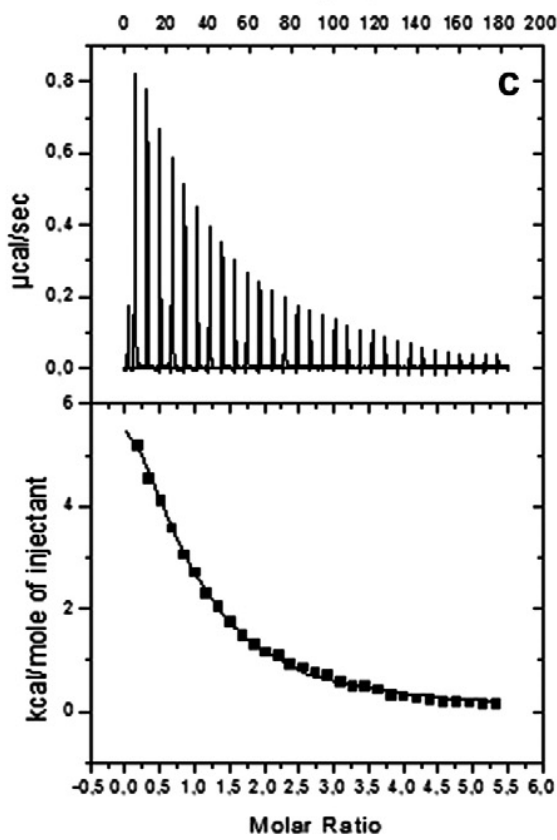

Fig. 3. Isothermal titration calorimetry results for the E1 synthetic peptides/HIV-1 FP interaction. Each figure corresponds to a different E1 peptide: $\mathrm{a}=\mathrm{P} 7$, $\mathrm{b}=\mathrm{P} 18$ and $\mathrm{c}=\mathrm{P} 22$.
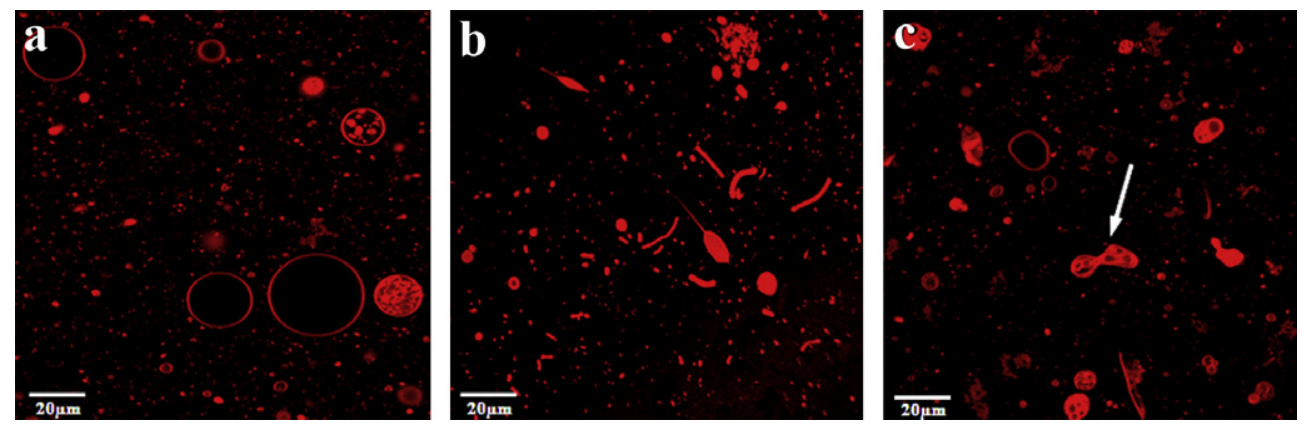

Fig. 4. Confocal microscopy images of (a) DMPC GUVs, (b) DMPC GUVs mixed with HIV-1 FP, showing broken liposomes and (c)DMPC GUVs mixed with HIV-1 FP, showing the fusion between two vesicles. 

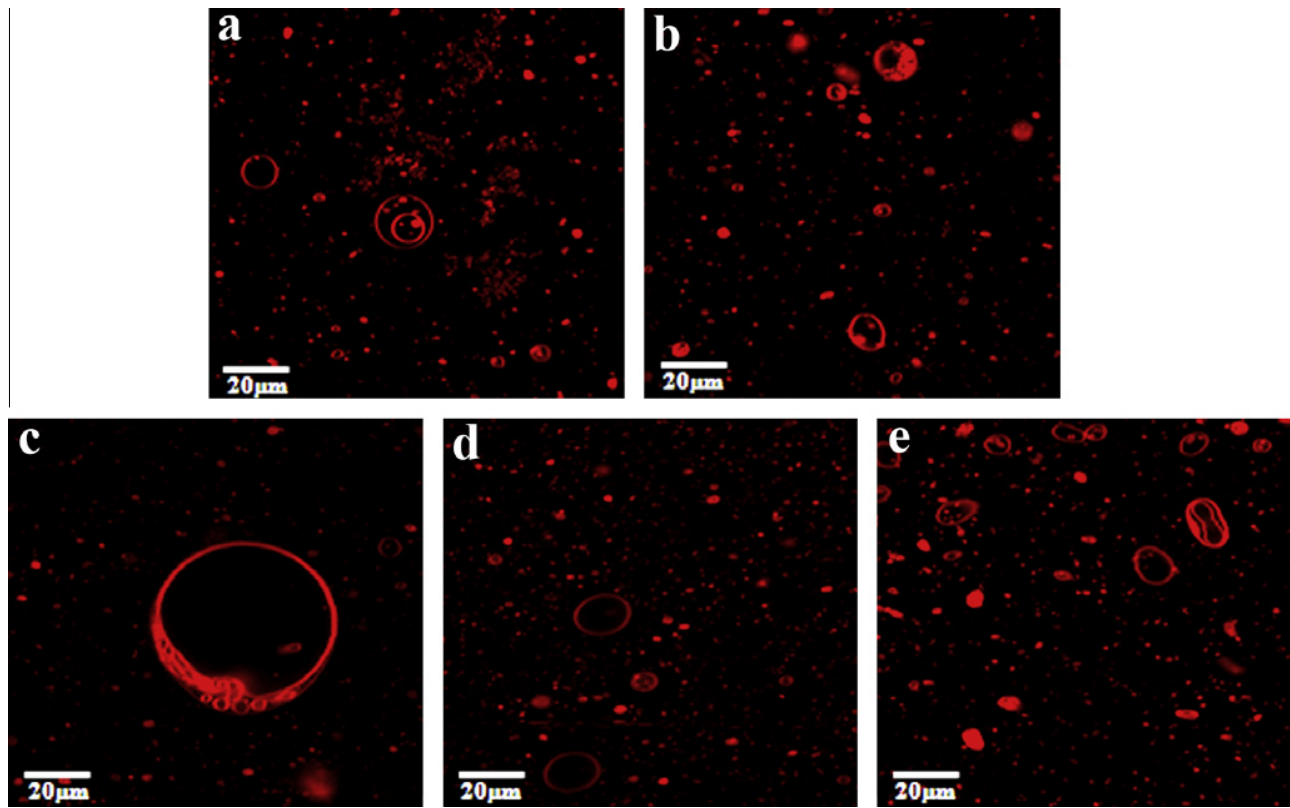

Fig. 5. Confocal microscopy images of DMPC GUVs mixed with HIV-1 FP, which was incubated with E1 synthetic peptides: P7 (a), P8 (b), P10 (c), P18 (d), and P22 (e).

\subsection{Confocal microscopy}

Giant vesicles are often used in biological research not only because their properties are similar to those of cell membranes [27], but also because of the size of the membrane model systems, which enables visualization by optical microscopy and micromanipulation of individual vesicles [37].

Rodriguez et al. [37] proved that the charge has an important influence on the vesicle formation, showing that the yield of clean unilamellar vesicles decreases when the amount of charged lipid is above $10 \%$. Since Rhodamine-PE is negatively charged, DMPC was chosen as a neutral phospholipid for preparing giant vesicles; PC, however, is a chief component of the cell membrane. We obtained vesicles from 10 to $50 \mu \mathrm{m}$. Firstly, HIV-1 FP was added to the vesicles. We then observed the appearance of elongated structures, corresponding to broken liposomes (Fig $4 \mathrm{~b}$ ). In addition, we saw that HIV-1 FP favored membrane fusion, shown in Fig. 4c.

HIV-1 FP was incubated with E1 synthetic peptides before adding them to the liposomes solution. The images in Fig. 5 show that GUVs are intact and therefore stable in the presence of the peptides mixture.

Confocal microscopy revealed what happens to the membranes when mixed with HIV-1 FP, providing additional evidence of the inhibiting activity of these five peptides, which correspond to the structural protein E1 of GBV-C.

\section{Conclusions}

We found five GBV-C related peptides with the ability to inhibit the interaction of the HIV-1 fusion peptide with model membranes.

When E1 peptides were mixed with HIV-1 FP, we observed different behaviors. On the one hand, some E1 peptides such as P7 and P18 increased their binding with liposomes in the presence of HIV-1 FP. We also found that less HIV-1 FP was bound to liposomes than when it was not mixed with peptides. In contrast, P10 and P22 decreased their binding to liposomes also reducing the percentage of HIV-1 FP bound to liposomes; P8 did not inhibit HIV-1 FP binding to liposomes, but the leakage assay revealed an inhibition of the pore formation caused by HIV-1 FP. Moreover, the dialysis experiments revealed that the percentage of HIV-1 FP remaining with E1 peptides was higher than the percentage remaining with the liposomes. Confocal microscopy revealed similar inhibition activity for all of E1 peptides.

Each peptide has a different behavior in the presence of HIV-1 FP. Equilibrium dialysis experiments indicate that the peptides interact in solution, which was corroborated by ITC experiments for P7, P18 and P22. However, we could not confirm the same for the other peptides. Additional assays for P8 and P10 should be carried out to understand how they interact with HIV-1 FP.

The different results obtained could indicate that HIV-1 FP and these peptides interact in different ways. The different methods that we used provide different glimpses of their behavior. There is evidence that the interactions are complex. It appears that the peptides are not interacting on the membrane only or in solution. Thus, the exact mechanism behind the interaction needs to be investigated further.

Thus, these peptides could be involved in the prevention of HIV1 entry by binding to the HIV-1 FP. In order to test the use of this peptide as an antiviral therapeutic agent, other assays are currently being performed.

\section{Acknowledgments}

This study was supported by project CTQ2006-15396-C02-02/ 01-BQU from the Secretaría de Estado de Investigación, Ministerio de Ciencia e Innovación, Dirección General de Programas y transferencia de conocimiento, Subdirección General de Proyectos de Investigación (Spain), and supported in part by NIH grant GM 068619. M.J. Sánchez-Martín is a recipient of an FPI program pre-doctoral grant. The authors are members of the consolidated research group by the Generalitat de Catalunya: Peptides and Proteins: physicochemical studies (2005SGR00278). The authors thank Dr. Marta Taulés Marí$\mathrm{n}$, of the Confocal Microscopy and Cellular Micromanipulation Unit, and Dr. Rafel Prohens López of the Fine Chemistry Unit, from the Barcelona Science Park, for heir invaluable assistance.

\section{Appendix A. Supplementary material}

Supplementary data associated with this article can be found, in the online version, at doi:10.1016/j.jcis.2011.04.053. 


\section{References}

[1] M.D. Resh, Biochim. Biophys Acta Mol. Cell Res. 1451 (1) (1999) 1-16.

[2] S. Michael, N. Edgar, K. Norman, B. Benjamin, K. Jürgen, W. Alfred, W. Herbert 5 (1999) 1239-1252.

[3] S. Thennarasu, D.-K. Lee, A. Tan, U. PrasadKari, A. Ramamoorthy, Biochim. Biophys. Acta Biomembr. 1711 (1) (2005) 49-58.

[4] R. Arnon, R.J. Horwitz, Curr. Opin. Immunol. 4 (4) (1992) 449-453.

[5] O.M. Vol'pinaIvanov, A. Surovoi, V.T. Ivanov, Biomed. Sci. 1 (1) (1990) 23-32.

[6] Y. Itoh, E. Takai, H. Ohnuma, K. Kitajima, F. Tsuda, A. Machida, S. Mishiro, T. Nakamura, Y. Miyakawa, M. Mayumi, Proc. Natl Acad. Sci. USA 83 (23) (1986) 9174-9178.

[7] H.G. Franquelim, L.s.M.S. Loura, N.C. Santos, M.A.R.B. Castanho, J. Am. Chem. Soc. 130 (19) (2008) 6215-6223.

[8] J. Cohen, Science 277 (5322) (1997) 32-33.

[9] N.A. Roberts, J.C. Craig, J. Sheldon, AIDS 12 (5) (1998) 453-460.

[10] R. Halasz, O. Weiland, M. Sallberg, Scand. J. Infect. Dis. 33 (8) (2001) 572-580.

[11] H.L. Tillmann, M.P. Manns, Antiviral Res. 52 (2) (2001) 83-90.

[12] J. Xiang, S. Wunschmann, D.J. Diekema, D. Klinzman, K.D. Patrick, S.L. George, J.T. Stapleton, N. Engl. J. Med. 345 (10) (2001) 707-714.

[13] J. Xiang, S.L. George, S. Wunschmann, Q. Chang, D. Klinzman, J.T. Stapleton, Lancet 363 (9426) (2004) 2040-2046.

[14] S. Jung, O. Knauer, N. Donhauser, M. Eichenmüller, M. Helm, B. Fleckenstein, H. Reil 19 (2005) 1267-1272.

[15] E. Herrera, S. Tenckhoff, M.J. Gomara, R. Galatola, M.J. Bleda, C. Gil, G. Ercilla, J.M. Gatell, H.L. Tillmann, I. Haro, J. Med. Chem. 53 (16) (2010) 6054-6063.

[16] J.R. Brender, K. Hartman, K.R. Reid, R.T. Kennedy, A. Ramamoorthy, Biochemistry 47 (48) (2008) 12680-12688.

[17] J.R. Brender, K. Hartman, L.M. Gottler, M.E. Cavitt, D.W. Youngstrom, A. Ramamoorthy, Biophys. J. 97 (9) (2009) 2474-2483.
[18] A. Ramamoorthy, D.K. Lee, T. Narasimhaswamy, R.P. Nanga, Biochim. Biophys. Acta 1798 (2) (2010) 223-227.

[19] R.F. Epand, W.L. Maloy, A. Ramamoorthy, R.M. Epand, Biochemistry 49 (19) (2010) 4076-4084.

[20] H. Ellens, J. Bentz, F.C. Szoka, Biochemistry 23 (7) (1984) 1532-1538.

[21] E. Kaiser, R.L. Colescot, B.D. Bossinge, P.I. Cook, Anal. Biochem. 34 (2) (1970) 595-598.

[22] N. Rojo, M.J. Gomara, M.A. Alsina, I. Haro, J. Pept. Res. 61 (6) (2003) 318-330.

[23] M.J. Hope, M.B. Bally, L.D. Mayer, A.S. Janoff, P.R. Cullis, Chem. Phys. Lipids 40 (2-4) (1986) 89-107.

[24] J.P. Reeves, R.M. Dowben, J. Cell Physiol. 73 (1) (1969) 49-60.

[25] A. Darszon, C.A. Vandenberg, M. Schonfeld, M.H. Ellisman, N.C. Spitzer, M. Montal, Proc. Natl. Acad. Sci. USA 77 (1) (1980) 239-243.

[26] D. Needham, T.J. McIntosh, E. Evans, Biochemistry 27 (13) (1988) 4668-4673.

[27] K. Tsumoto, H. Matsuo, M. Tomita, T. Yoshimura, Colloids Surf. B 68 (1) (2009) 98-105.

[28] H. Ellens, J. Bentz, F.C. Szoka, Biochemistry 24 (13) (1985) 3099-3106

[29] M. Smolarsky, D. Teitelbaum, M. Sela, C. Gitler, J. Immunol. Methods 15 (3) (1977) 255-265.

[30] U. Pick, Arch. Biochem. Biophys. 212 (1) (1981) 186-194.

[31] W.C. Wimley, S.H. White, Biochemistry 32 (25) (1993) 6307-6312.

[32] S.H. White, W.C. Wimley, A.S. Ladokhin, K. Hristova, Methods Enzymol. 295 (1998) 62-87.

[33] S.H. White, W.C. Wimley, A.S. Ladokhin, K. Hristova, Energ. Biol. Macromol., Pt B 295 (1998) 62-87.

[34] R. A. Gatti, A. Ostborn, A. Fagraeus, vol. 113 (1974) pp. 1361-1368.

[35] M. Wu, S.-Q. Nie, Y. Qiu, K.-C. Lin, S.-X. Wang, S.-F. Sui, Peptides Biol. Chem. (2002) 104-107.

[36] S. Thennarasu, R. Huang, D.K. Lee, P. Yang, L. Maloy, Z. Chen, A. Ramamoorthy, Biochemistry 49 (50) (2010) 10595-10605.

[37] N. Rodriguez, F. Pincet, S. Cribier, Colloids Surf. B 42 (2) (2005) 125-130. 